\title{
Diaphragmatic Plication: Retrospective Study with 54 Patients
}

\author{
Sezai Çelik $^{1^{*}}$, Serhan Tanju ${ }^{2}$, İsa Döngel ${ }^{2}$, Onur Gürer ${ }^{1}$, Alper Toker $^{2}$ \\ ${ }^{1}$ Cardiothoracic Surgery Department, Medicana Hospitals, Istanbul, Turkey; ${ }^{2}$ Thoracic Surgery Department, Istanbul Medical Faculty, \\ Istanbul University, Istanbul, Turkey. \\ Email: "dr_sezaicelik@hotmail.com
}

Received August $7^{\text {th }}, 2013$; revised August $27^{\text {th }}, 2013$; accepted September $4^{\text {th }}, 2013$

Copyright (C) 2013 Sezai Çelik et al. This is an open access article distributed under the Creative Commons Attribution License, which permits unrestricted use, distribution, and reproduction in any medium, provided the original work is properly cited.

\begin{abstract}
Objective: This study seeks to evaluate the results of surgery performed according to the etiological causes of diaphragmatic eventration or paralysis. Method: Files of 54 patients (35 males, 19 females; mean age: $39.1 \pm 3.01$ years) who had undergone diaphragm plication between January 2005 and June 2011 in two clinics located in Istanbul were studied in terms of pulmonary spirometry, applied surgical procedure, duration of hospitalization, morbidity, and mortality. Results: In diaphragm plications, observed etiologies were isolated diaphragmatic eventration without phrenic nerve injury (Group 1) in 20 (37\%) patients due to blunt thoracic trauma; Group 2 (thymoma in 19 (35.2\%) patients; lung cancer in 7 (12.9\%) patients; mediastinal tumor in $3(5.6 \%)$ patients) and congenital heart surgery (Group 3$)$ in 5 $(9.3 \%)$ patients. The mean time to plication was 7.4 months in Group 1. The mean duration of hospitalization was 4 days in Group 1, 6.2 days in Group 2, 11.8 days in Group 3. Mean forced vital capacity, forced expiratory volume at 1 second improved by $17 \%, 20.3 \%$, respectively $(\mathrm{p}<0.005)$ in Group 1 . In Group 1, mean dyspnea-related hospital admission before plication was 2.4 times. At the end of 6 months after plication mean dyspnea-related hospital admission was 0 time. All of them returned to daily activities or their job within 6 months in Group 1. Postoperative mortality was observed in $2(3.7 \%)$ patients in Group 3 while the overall complication rates were $24 \%$. The morbidity rates were $8 \%, 27.5 \%, 60 \%$, respectively; and the mortality rates were $0 \%, 0 \%, 40 \%$, respectively. Conclusion: As a result, it could be suggested that early and timely performed plications for diaphragmatic eventration improves functional status and assesses a shorter lenght of stay. On the other hand,simultaneously performed plications in intraoperative phrenic nerve resections can be performed with acceptable morbidity and no mortality. In diaphragmatic paralysis due to congenital heart surgery, morbidity and mortality rate is still high.
\end{abstract}

Keywords: Diaphragm Plication; Paralysis; Eventration; Phrenic Nerve Resection

\section{Introduction}

The diaphragm is an anatomical structure consisting of two dome-shaped muscles and an aponeurosis separating the abdomen and the thorax. The main anatomical function of the diaphragm is to separate the thoracic and abdominal cavities; however, its main physiological function is its role in ventilation. Diaphragm is an important muscle as it is involved in $75 \%$ of the body's total inhalation activity, and each centimeter of vertical movement contributes to 300 to $400 \mathrm{ml}$ of air during normal breathing [1]. Diaphragmatic eventration or paralysis observed in adults is rarely observed. However, cardiothoracic surgery, mediastinal pathologies, thymus surgery, tumors,

\footnotetext{
${ }^{*}$ Corresponding author.
}

infections, muscle-nerve disease, thoracic and mediastinal radiotherapy, injuries, and granulomatous diseases are the most frequent reasons for diaphragmatic paralysis [2-4]. Paralysis of diaphragm is a severe complication of cardiothoracic surgery carrying significant morbidity and mortality [5]. The aim of the study is to evaluate the results of surgery performed according to the etiological causes of diaphragmatic eventration or paralysis.

\section{Patients and Methods}

Records of patients that had undergone diaphragm plication for diaphragmatic eventration or paralysis between January 2005 and June 2011 at Istanbul University, Istanbul Medical Faculty, Thoracic Surgery Department and Medicana Hospital's Thoracic Surgery Department 
in Istanbul were studied retrospectively in terms of pulmonary spirometry, applied surgical procedure, duration of hospitalization, morbidity, and mortality and divided into three groups according to etiologies. Fifty-four patients undergoing plication for diaphragmatic eventration or paralysis were included in the study. Thirty-five (64.8\%) of these patients were male, and the ages of the patients ranged from 1 to 76 years (Mean age: $39.1 \pm 3.01$ ). In diaphragmatic pathologies, the surgical approach differed according to the shape, localization, and status of the lesion.Hence, patients were positioned according to the surgical approach to be performed. In mediastinal lesions, sternotomy was performed under general anesthesia, while diaphragm plication was performed during single lung ventilation by right or left mini-lateral thoracotomy through the 8th intercostal space and by bilateral mini-lateral thoracotomy through the 8th intercostal space in those having a history of congenital heart surgery.

Respiratory function test and fluoroscopic sniff test were performed before surgery in patients thought to have primary pathology of diaphragm. Radiographically, twoway plain radiographies were obtained for all the patients while computed tomography was obtained when deemed necessary. Surgically, diaphragm plication was generally performed starting from the mediasten with monoflament $1 / 0$ non-absorbable sutures passing from posterior to anterior and protecting the organs beneath the diaphragm by lifting the diaphragm with a clamp or by phrenotomy (Figure 1). In general, 5 - 8 successive sutures were sufficient for a diaphragm plication, and a mesh could support a delicate diaphragm.

\section{Statistics}

Continuous data are expressed as the mean plus or minus the standart deviation of the mean except where otherwise indicated. Differences between categorical variables were evaluated by Fisher's exact test. Differences be- tween continuous variables were measured by the twotailed Student test. Statistical significance was accepted as $\mathrm{p}$ less than 0.05 .

\section{Results}

For the diaphragm plications, the observed etiologies were isolated diaphragmatic eventration without phrenic nerve injury (Group 1) in 20 (37\%) patients; Group 2, n = 29 (thymoma in 19 (35.2\%) patients; lung cancer in 7 (12.9\%) patients; mediastinal germ cell tumor in $3(5.6 \%)$ patients) and congenital heart surgery in $5(9.3 \%)$ patients (Group 3 ), (Figure 2). Thirty-four (63\%) of the diaphragm plications resulted from resection due to invasion of the phrenic nerve by tumor or from damage due to congenital heart surgery. Surgically, a right thoracotomy was performed in $12(22.2 \%)$ patients, left thoracotomy in $27(50.0 \%)$ patients, bilateral thoracotomy in $5(9.3 \%)$ patients, and a sternotomy was performed in $10(18.5 \%)$ patients (Table 1).

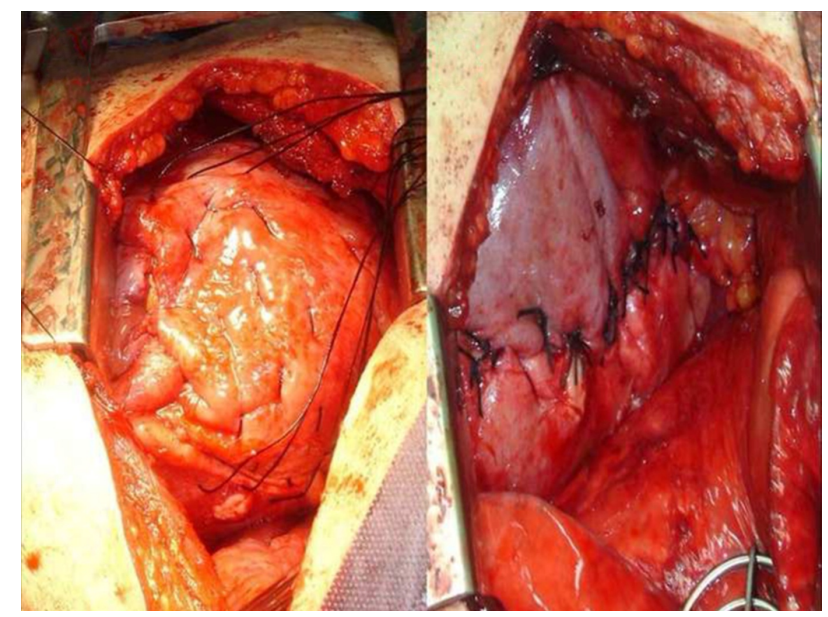

Figure 1. Photographic views of diaphragm eventration with intraoperative sutures and diaphragm plication.

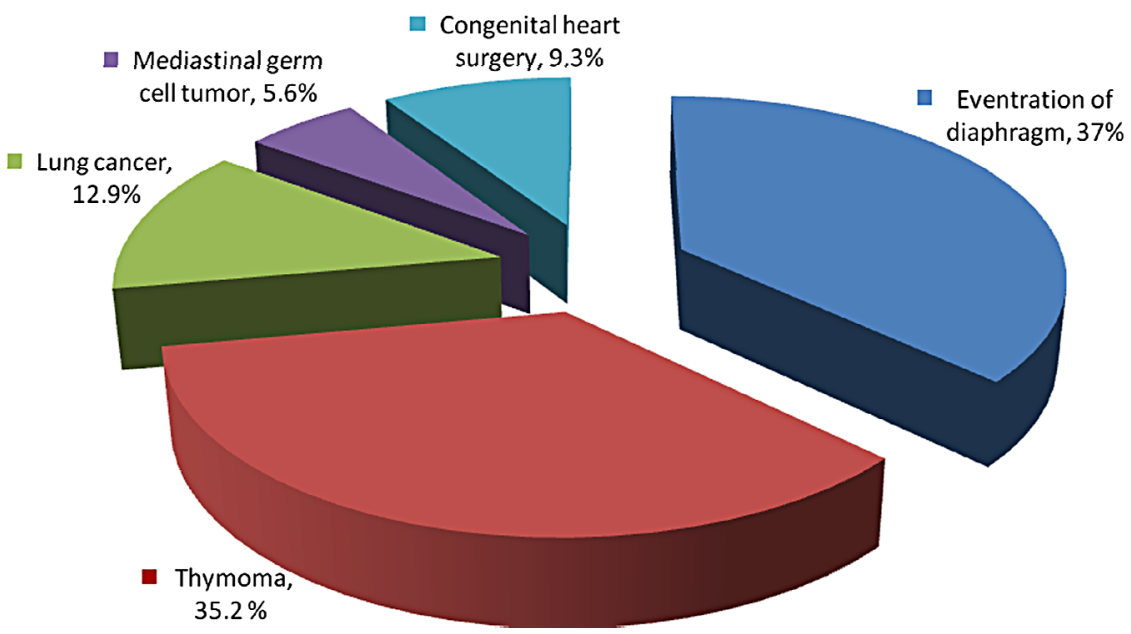

Figure 2. Etiological reasons in diaphragm plication. 
Table 1. Surgical procedures in diaphragm plication.

\begin{tabular}{|c|c|c|c|c|c|c|}
\hline & & $\begin{array}{l}\text { Number of } \\
\text { patients }\end{array}$ & $\begin{array}{c}\text { Right } \\
\text { thoracotomy (\%) }\end{array}$ & $\begin{array}{c}\text { Left } \\
\text { thoracotomy (\%) }\end{array}$ & $\begin{array}{c}\text { Bilateral } \\
\text { thoracotomy (\%) }\end{array}$ & Sternotomy (\%) \\
\hline \multirow{5}{*}{$\begin{array}{l}\text { Causes related to phrenic } \\
\text { nerve resection or injury }\end{array}$} & of diaphragm & 20 & $4(20)$ & $16(80)$ & - & - \\
\hline & Thymoma & 19 & $3(15.8)$ & $7(36.8)$ & - & $9(47.4)$ \\
\hline & Lung cancer & 7 & $4(57.1)$ & $3(42.9)$ & - & - \\
\hline & Mediastinel germ cell tumor & 3 & $1(33.3)$ & $1(33.3)$ & - & $1(33.3)$ \\
\hline & Congenital heart surgery & 5 & - & - & $5(100)$ & - \\
\hline \multicolumn{2}{|c|}{ TOTAL } & 54 & $12(22.2)$ & $27(50.0)$ & $5(9.3)$ & $10(18.5)$ \\
\hline
\end{tabular}

The mean time to plication was 7.4 months in Group 1 . The mean duration of hospitalization was 4 days in Group 1, 6.2 days in Group 2, 11.8 days in Group 3. Mean forced vital capacity, forced expiratory volume at $1 \mathrm{sec}-$ ond improved by $17 \%, 20.3 \%$, respectively $(\mathrm{p}<0.005)$ in Group 1 (Table 2). In group 1, mean dyspnea-related hospital admission before plication was 2.4 times. At the end of 6 months after plication mean dyspnea-related hospital admissions were 0 time. All of them returned to daily activities or their job within 6 months in Group 1 (Table 2). Postoperative mortality was observed in $2(3.7 \%)$ patients in Group 3 while the overall complication rates were 24\% (Table 3).

\section{Discussion}

Although etiologies of diaphragmatic eventration and paralysis are different, their treatments are the same. Diaphragmatic eventration is the most frequently encountered primary pathology of the diaphragm. Diaphragmatic eventration is a clinic situation characterized by relocalization of the abdominal viscrea into the thorax. While it is observed particularly at pediatric age, it is encountered rarely in adults. Generally, it is right sided and asymptomatic [1]. The most frequently reported causes of acquired diaphragmatic eventration are previous intrathorax surgery or trauma [6]. Most of times, treatment is not necessary in diaphragmatic eventration. However, treatment is applied when there are symptoms, such as respiratory distress, poor exercise tolerance, recurrent pneumonia, chronic bronchitis, cardiac arrhythmia, and functional gastric disorders [6,7]. In the current study, diaphragm plication was found to have been performed in $20(37 \%)$ patients due to diaphragmatic eventration. Four of these patients had a right mini-lateral thoracotomy, while 16 had a left mini-lateral thoracotomy through the 8 th intercostal space. The aim of plication is to increase lung compliance on the concerned side, decrease paradoxical movement, and to make the medistinum more stable by flattening the eventrated hemidiaphragm $[8,9]$. Some authors have reported that a respiratory function test when standing or at rest, a fluoroscopic sniff-test to observe paradoxical movement of diaphragm, or an ultrasonography are sufficient and no other examinations
Table 2. Functional status at six month follow up for patients treated with diaphragm plication in Group 1(n=20).

\begin{tabular}{cc}
\hline Pulmonary function tests & $\begin{array}{c}\text { Mean changes in percent for } \\
\text { each parameter }\end{array}$ \\
\hline Forced expiratory volume at 1second & $+17 \%$ \\
Forced vital capacity & $+20.3 \%$ \\
Return to daily activities & +20 \\
Dyspnea-related hospital readmission & 0 \\
\hline
\end{tabular}

are required $[10,11]$. In the current study, a respiratory function test and fluoroscopic sniff-test were found to have been performed in patients thought to have isolated diaphragm eventration. In our previous study [12] analyzing long term (32.9 months on average) respiratory function tests of 11 patients undergoing unilateral diaphragm plication found that spirometric findings improved significantly after plication. In current study, significant improvements for forced expiratory volume at 1 second and forced vital capacity were seen in Group 1. Additional examinations were performed only in patients with suspected pathologies due to tumors with phrenic nerve involvement. While in diaphragmatic paralysis in infants and young children there is consensus about early plication, in adults there is less uniformity about the timing of surgical plication that is usually suggested and applied at a later time [13]. In our study,the mean time to plication was 7.4 months in Group 1. Our current experience, opposite the previous study [12], we advocate that long waiting period in certain patients for plication can cause more perioperative complications.

Thymoma, arising from thymic epithelial cells and associated with non-neoplastic $\mathrm{T}$ lymphocytes to varying degrees, is the most common tumor of anterior mediastinum. In our study, diaphragm plication was performed due to phrenic nerve resection in $19(35.2 \%)$ patients having phrenic nerve involvement of thymoma. It has been advocated that a complete resection is the most appropriate treatment choice in determining long-term survival [14,15].

Lung and mediastinal cancers may affect the diaphragm by invading the phrenic nerve. In the current study, diaphragm plication was performed due to phrenic nerve resection in $7(12.9 \%)$ patients with phrenic nerve involvement of lung cancer. Mediastinal germ cell tumors are aggressive, and they frequently invade the phrenic 
Table 3. Complication rates in terms of diagnosis in diaphragm placations.

\begin{tabular}{cccccccccccc}
\hline & \multirow{2}{*}{$\begin{array}{c}\text { Number } \\
\text { of patients }\end{array}$} & Mortality & & None & Atelectasis & $\begin{array}{c}\text { Respiratory } \\
\text { failure }\end{array}$ & Bleeding & İleus $\begin{array}{c}\text { Wound } \\
\text { infection }\end{array}$ & \begin{tabular}{c} 
Pneumonia \\
\cline { 4 - 10 }
\end{tabular} & $\begin{array}{c}\text { Chylothorax } \\
\text { Prolonged } \\
\text { air leak }\end{array}$ \\
\hline $\begin{array}{c}\text { Eventration of } \\
\text { diaphragm }\end{array}$ & 20 & - & 18 & - & 1 & - & 1 & - & - & - \\
$\begin{array}{c}\text { Thymoma } \\
\text { Lung cancer }\end{array}$ & 19 & - & 13 & 1 & 1 & 1 & - & 1 & 1 & 1 & - \\
$\begin{array}{c}\text { Mediastinal } \\
\text { germ cell tumor }\end{array}$ & 3 & - & 7 & - & - & - & - & - & - & - & - \\
$\begin{array}{c}\text { Congenital } \\
\text { heart surgery }\end{array}$ & 5 & - & 1 & - & - & 1 & - & - & - & - & 1 \\
TOTAL (\%) & 54 & $2(3.7)$ & $39(72.1)$ & $1(1.9)$ & $5(9.3)$ & $2(3.7)$ & $1(1.9)$ & $1(1.9)$ & $1(1.9)$ & $1(1.9)$ & $1(1.9)$ \\
\hline
\end{tabular}

nerve. In the current study, diaphragm plication was found to have been performed due to phrenic nerve resection in $3(5.6 \%)$ patients having phrenic nerve involvement due to mediastinal germ cell tumor. In the surgical procedure, phrenic nerve resection leads to hemi-diaphragmatic paralysis whether it is right-sided or left-sided. For this reason, vital capacity is reduced by $20 \%$ to $30 \%$ [1]. While this does not generally cause a respiratory difficulty in normal adults, severe respiratory difficulty is observed in elder patients (over 80 years old) having severe myasthenia gravis, myotonic dystrophy, or chronic obstructive pulmonary disease. Hence, bilateral phrenic nerve resections especially should be avoided. In their study, Yano et al. [16] reported how patients having phrenic nerve invasion should be handled, and that a combined resection improved treatment but phrenic nerve resection could have a deteriorating effect on post-operative life quality and cause various complications in Masaoka stage 3 thymoma. However, they reported that preservation of the involved phrenic nerve may affect the survival of thymoma patients negatively, but no patients undergoing phrenic nerve resection due to phrenic nerve invasion died during intraoperative or postoperative periods, and one patient died of chronic respiratory failure 29 months after the operation. In our study, morbidity rate was $27.5 \%$ and no mortality in Group 2 .

Tokunaga et al. [17] performed intraoperative unilateral diaphragm plication in 13 patients (6 with lung cancer, 6 with mediastinal tumor, and 1 with mesothelioma) undergoing phrenicotomy to prevent postoperative complications. A year after the operation, 10 (77\%) patients had no postoperative complications, $3(23 \%)$ had pulmonary complications, and $2(15 \%)$ required prolonged mechanical ventilation. They also reported that postoperative lung function after plication was similar to predicted postoperative lung function, and that diaphragm plication was effective to prevent postoperative pulmonary complications and to preserve postoperative lung function in such patients.

In a review on etiology, pathophysiology, diagnosis, and treatment of diaphragmatic eventration and paralysis in adults, Shawn et al. [18] reported that diaphragm plication was only indicated for symptomatic patients with diaphragmatic paralysis or eventration. They also reported that there was a variety of open and minimally invasive transthoracic and transabdominal techniques and that the short-term outcomes after minimally invasive plication were promising but long-term results had yet to be published. So, it could be suggested that minimally invasive techniques may be more adequate in isolated diaphragmmatic eventrations.

Following congenital heart surgery, diaphragmatic paralysis may be observed due to phrenic nerve injury. Nearly $64 \%$ of the diaphragmatic paralysis occurring in cardiovascular surgery resulted from phrenic nerve injury. The incidence of diaphragmatic paralysis after pediatric cardiac surgery has been reported as $0.28 \%-5.4 \%$ [19]. In 100 patients (50 infants and 50 children) under 15 years old, Mok et al. [20] found the incidence of diaphragmatic paralysis as $10 \%$ by preoperative and postoperative (within 72 hours of operation) transcutaneous phrenic nerve stimulation. In the current study, bilateral mini-thoracotomy and diaphragmatic plication were performed in the same session in $5(9.3 \%)$ pediatric patients having bilateral diaphragmatic paralysis following congenital heart surgery.

In the current study, no complications were observed in $39(72.2 \%)$ patients. Respiratory failure was observed in $5(9.3 \%)$ patients, while 3 of these patients were those undergoing bilateral diaphragmatic plication after congenital heart surgery. Postoperative hemorrhage was seen in $2(3.7 \%)$ patients with thymoma and mediastinal germ cell. Atelectasis, ileus, wound infection, pneumonia, chylothorax, and prolonged air leak were each observed in different individual patients. Mortality was observed in 2 (3.7\%) patients undergoing diaphragmatic plication following congenital heart surgery and requiring postoperative ventilator dependency and close follow up. In this patients, morbidity, mortality, and complication ratios were significantly higher compared to those in others. 
There is almost always failure to wean for mechanical ventilation in infants and young children with diaphragmatic paralysis after cardiac surgery. El Tantawy et al. [21] reported that patients with diaphragmatic paralysis had significantly prolonged ventilation duration, higher incidence of pneumonia, longer duration of intensive care unit, and mortality as compared to unaffected patients. They also reported that early plication for certain patients may lead to improved outcomes.

As a result, we suggest that early and timely performed plications for diaphragmatic eventration improves functional status and assesses a shorter lenght of stay. On the other hand, simultaneously performed plications in intraoperative phrenic nerve resections can be performed with acceptable morbidity and no mortality. In diaphragmatic paralysis and plication due to congenital heart surgery, morbidity and mortality rate is still high.

\section{REFERENCES}

[1] T. W. Shields, "Diaphragmatic Function, Diaphragmatic Paralysis, and Eventration of the Diaphragm," In: T. W. Shields, J. Locicero and R. B. Ponn, Eds., General Thoracic Surgery, Vol. 1, 6th Edition, Lippincott, Williams and Wilkins, Philadelphia, 2004, pp. 740-745.

[2] J. M. Piehler, P. C. Pairolero, D. R.Gracey and P. E. Bernatz, "Unexplained Diaphragmatic Paralysis: A Harbinger of Malignant Disease?" The Journal of Thoracic and Cardiovascular Surgery, Vol. 84, No. 6, 1982, pp. 861-864.

[3] M. Ribet and J. L. Linder, "Plication of the Diaphragma for Unilateral Eventration or Paralysis," European Journal Cardio-Thorac Surgery, Vol. 6, No. 7, 1992, pp. $357-$ 360.

[4] R. W. Light, "Disorders of the Pleura, Mediastinum, and Diaphragm,” In: E. Braunwald, A. C. Fauci, D. L. Casper, et al., Eds., Harrison's Principles of Internal Medicine, 15th Edition, McGraw-Hill, New York, 2001, pp. 15131516.

[5] T. P. Hüttl, M. W. Wichmann, B. Reichart, T. K. Geiger, et al., "Paralysis of the Diaphragm Is a Severe Complication of Cardiothoracic Surgery Carrying Significant Morbidity and Mortality," Surgery Endoscopy, Vol. 18, No. 3, 2004, pp. 547-551. doi:10.1007/s00464-003-8127-8

[6] T. Tiryaki, Z. Livanelioğlu and H. Atayurt, "Eventration of the Diaphragm," Asian Journal Surgery, Vol. 29, No. 1, 2006, pp. 8-10. doi:10.1016/S1015-9584(09)60285-2

[7] P. Gatzinsky and V. Lepore, "Surgical Treatment of a Large Eventration of the Left Diaphragm," European Journal Cardio-Thoracic Surgery, Vol. 7, No. 5, 1993, pp. 271-274. doi:10.1016/1010-7940(93)90216-X

[8] C. D. Wright, J. G. Williams, C. M. Ogilvie and R. J. Donnelly, "Results of Diaphragmatic Plication for Unilateral Diaphragmatic Paralysis," The Journal of Thoracic Cardiovascular Surgery, Vol. 90, No. 2, 1985, pp. 195198.

[9] F. Oğuzkaya, M. Bilgin, Y. Akçalı, C. Kahraman and A.
Şahin, "Diaphragmatic Plication in Unilateral Diaphragmatic Paralysis or Evantration in Adults," Türk Gögüus Kalp ve Damar Cerrahisi Dergisi, Vol. 6,1998, pp. 6367.

[10] D. A. Simansky, M. Paley, Y. Refaely and A. Yellin, "Diaphragm Plication Following Phrenic Nerve İnjury: A Comparison of Paediatric and Adult Patients," Thorax, Vol. 57, No. 7, 2002, pp. 613-616. doi:10.1136/thorax.57.7.613

[11] B. R. Celli, "Respiratory Management of Diaphragm Paralysis," Seminars Respiratory Critical Care Medicine, Vol. 23, No. 3, 2002, pp. 275-281. doi:10.1055/s-2002-33036

[12] S. Celik, M. Celik, B. Aydemir, C. Tunckaya, T. Okay and I. Dogusoy, "Long-Term Results of Diaphragmatic Plication in Adults with Unilateral Diaphragm Paralysis," Journal of Cardiothoracic Surgery, Vol. 5, 2010, p. 111. doi:10.1186/1749-8090-5-111

[13] K. Tsakiridis, A. N. Visouli, P. Zarogoulidis, N. Machairiotis, et al., "Early Hemi-Diaphragmatic Plication through a Video-Asisted Mini-Thoracotomy in Postcardiotomy Phrenic Nerve Paresis," Journal of Thoracic Disease, Vol. 4, No. 1, 2012, pp. 56-58.

[14] K. Kondo and Y. Monden, "Therapy for Thymic Epithelial Tumors: A Clinical Study of 1320 Patients from Japan," Annals of Thoracic Surgery, Vol. 76, No. 3, 2003, pp. 878-884.

[15] K. Nakagawa, H. Asamura, Y. Matsuno, K. Suzuki, H. Kondo, A. Maeshima, et al., "Thymoma: A Clinicopathologic Study Based on the New World Health Organization Classification," Journal of Thoracic Cardiovascular Surgery, Vol. 126, No. 4, 2003, pp. 1134-1140. doi:10.1016/S0022-5223(03)00798-0

[16] M. Yano, H. Sasak, S. Moriyama, O. Kawano, Y. Hikosaka, A. Masaoka and Y. Fujii, "Preservation of Phrenic Nerve Involved by Stage III Thymoma," Annals of Thoracic Surgery, Vol. 89, No. 5, 2010, pp. 1612-1619. doi:10.1016/j.athoracsur.2010.01.057

[17] T. Tokunaga, N. Sawabata, Y. Kadota, T. Utsumi, M. Minami, et al. "Efficacy of İntra-Operative Unilateral Diaphragm Plication for Patients Undergoing Unilateral Phrenicotomy during Extended Surgery," European Journal of Cardio-Thoracic Surgery, Vol. 38, No. 5, 2010, pp. 600-603. doi:10.1016/j.ejcts.2010.03.012

[18] S. Shawn, M. D. Groth, S. Rafael and M. D. Andrade, "Diaphragm Plication for Eventration or Paralysis: A Review of the Literature," Annals of Thoracic Surgery, Vol. 89, No. 6, 2010, pp. 2146-2150. doi:10.1016/j.athoracsur.2010.03.021

[19] A. L. J. Arreola, U. Bauersfeld, U. G. Stauffer, O. Baenziger and V. Bernet, "Incidence and Treatment of Diaphragmatic Paralysis after Cardiac Surgery in Children," European Journal of Cardio-Thoracic Surgery, Vol. 27, No. 1, 2005, pp. 53-57. doi:10.1016/j.ejcts.2004.10.002

[20] Q. Mok, R. Ross-Russel, D. Mulvey and E. A. Shinebourne, "Phrenic Nerve İnjury in İnfants and Children Undergoing Cardiac Surgery," British Heart Journal, Vol. 65 , No. 5, 1991, pp. 287-292. doi:10.1136/hrt.65.5.287 
[21] A. E. El Tantawy, S. Imam, H. Swaky and T. Salah, "Diaphragmatic Nerve Palsy after Cardiac Surgery in Children in Egypt. Outcome and Debate in Management," World
Journal of Pediatrics \& Congenital Heart Surgery, Vol. 4, No. 1, 2013, pp. 19-23. doi:10.1177/2150135112454444 